\title{
"UNA VIEJA BARBUDA QUE SE DICE CELESTINA": NOTAS ACERCA DE LA PRIMERA CARACTERIZACIÓN DE CELESTINA $^{1}$
}

\author{
Jacobo Sanz Hermida \\ Universidad de Salamanca
}

No es nuevo a estas alturas volver a llamar la atención sobre un hecho que ha sido destacado ya abundantemente, como es el que Celestina se nos presente con toda clase de detalles, frente al resto de los personajes que han de conformarse, en el mejor de los casos, con una descripción estereotipada, y en su mayor parte con tan sólo el nombre. Si como sabemos un interés muy especial movió al autor primigenio, y más tarde a Rojas, a detenerse en la confección de un personaje cuýa complejidad psicológica debía estar acorde a una descripción física pormenorizada, a fin de que su obra avanzase por unos derroteros que nos son conocidos; creo que resulta necesario detenerse un poco más en un aspecto que ha pasado inadvertido por la crítica celestinesca y que en mi opinión dará luz no sólo a la relación con otras figuras de alcahuetashechiceras que encontramos en nuestra literatura medieval, sino que además sirve para explicarnos un pasaje de esta obra que por ahora no ha sido anotado.

Como el propio título indica, mis reflexiones ambulan alrededor de la primera referencia caracterizadora que poseemos de Celestina,

1 Este artículo tiene su origen en la comunicación que presenté en el $V$ Colloquium on Xvc Literature organizado por el Medieval Hispanic Research Seminar del Department of Hispanic Studies del Queen Mary and Westfield College, (Londres, 25-26 de junio de 1993). En él se han incorporado novedades así como todas aquellas acertadas sugerencias que se me hicieron durante dicho Coloquio. 
cuando Sempronio trata de calmar la locura que invade a Calisto mediante la intervención de una mujer que describe a su amo como "un vieja barbuda que se dize Celestina." Es precisamente el epíteto de "vieja barbuda" el que me interesa comentar, pues en sí encierra unas significaciones que no eran desconocidas a los lectores del momento, pero que con el paso del tiempo hemos perdido en gran medida.

En una primera instancia una mujer barbuda es aquella que afea y desmejora su rostro con un ornato que en nada le pertenece, la barba. ${ }^{2}$ Pues después de todo, como señalaba $\mathrm{S}$. Isidoro, "Barbam veteres vocaverunt, quod virorum sit non mulierum. ${ }^{3}$ Ahora bien, si la barba es un elemento en principio masculino es porque existe una notable diferencia entre la complexión del hombre y de la mujer, pues como de sobra es sabido, siguiendo la teoría clásica de los humores, el hombre era cálido y seco, frente a la mujer que es fría y húmeda. Por otra parte los

${ }^{2}$ El recorrido que a continuación hago sobre el problema de la barba en la mujer ha sido ya abordado en algunos trabajos míos. Véase «Mulierem barbatam eminus esse salutandam" en Figuras de la exclusión femenina: ermitañas, monjas visionarias, barbudas, mujeres pilosas..., I Curso del Aula Salamanca. Curso celebrado en mayo de 1990 en la Universidad de Salamanca, sin haberse publicado hasta ahora sus Actas (Ponencia presentada en colaboración con Fernando R. de la Flor); y también con Fernando R. de la Flor, "La puella pilosa: hacia una lectura iconológica de la mujer barbuda en la pintura española del Siglo de Oro; de Sánchez Cotán a José de Ribera (Pasando por Sebastián de Covarrubias)," en Actas del VIII Congreso Nacional de Historia del Arte, II, Cáceres: Universidad, 1993, pp. 763-770; “Aspectos fisiológicos de la Dueña Dolorida: la transformación de la mujer en hombre» en Actas del III Coloquio Internacional de la Asociación de Cervantistas, Barcelona: Anthropos, 1993, pp. 463-472; y mi reciente «Ensoñación y transformismo: la parodia erótica en El sueño de la viuda de fray Melchor de la Serna," en Actas del III Congreso de la Asociación Internacional de Siglo de Oro, Toulouse [En prensa].

3 San Isidoro, Etimologías, ed. J. Oroz Reta y M. Marcos Casquero, I, Madrid: $B A C, 1982$, p. 303. La barba como símbolo de la virilidad ha sido utilizada en múltiples textos literarios; valgan al caso, como ejemplo, las palabras de Angis a Darino que recoge Pedro Manuel de Urrea en su Penitencia de amor: “No an de ser los ombres todos en burlas, que se avezan a çufrir injurias, mas las más vezes vestidos de fieltro y de cuero y morir en el campo y no en la cama; llevar la barba creçida porque en todas las cosas que el ombre se puede apartar de pareçer muger es razón que lo haga. Como sea la barba de las cosas que se aparta el ombre de pareçer muger va bien con la barba» (ed. de José Luis Canet Vallés en su De la comedia humanistica al teatro representable, Valencia: UNED-Universidad de Sevilla-Universitat de València, 1993, p. 153). Agradezco a mi buena amiga Maribel Toro la noticia de esta cita. 
humores malignos, y por lo tanto superfluos, son eliminados del cuerpo humano en forma de espíritos, según la medicina galénica, de manera que, como indicaba S. Alberto Magno, «Los humores, pues, que forman la barba en los hombres hacen los menstruos en las mujeres, que fluyen dos o una vez por mes.»"

Según esto hemos de pensar que sería bastante normal que aquellas mujeres que alcanzasen una edad avanzada en la que no pudieran de forma natural "purgar sus flores," habrían de eliminar estos malignos humores por otro medio, $y$, por qué no, mediante la aparición de la barba. Esta explicación satisface la primera noticia que tenemos de Celestina, "una vieja barbuda," pues como sabemos Rojas nos dice en dos ocasiones la edad de este personaje, "seis de dozenas de años" en boca de Pármeno y "sesenta años" según quiere la propia Celestina. ${ }^{5}$ Con esto tendriamos tan sólo que Celestina es una mujer anciana, con una barba que la afea y cuya génesis puede ser explicada desde un punto de vista médico.

En este mismo ámbito, encontramos numerosos ejemplos en la literatura medieval castellana en los que la barbuda viene a representar el ideal contrario femenino; como cuando al hablar don Amor de la perfecta mujer al Arcipreste le indica claramente: "Guár[da]te que non sea bellosa nin barbuda." ${ }^{6} \mathrm{E}$ incluso en algunos casos no resulta rara su equiparación con la salvaje, como la serrana con la que se encuentra Carvajales tras su salida de Roma a la que describe, entre otros muchos, con calificativos tan ilustrativos como: "calva, çeniunta et muy nariguda,/ tuerta de un oio, ynfibia, barbuda.»" Pues después de todo, como dice

4 San Alberto Magno, The Book of Secrets, ed. Michael R. Best y Frank H. Breihtman, Oxford: Clarendon Press, 1973, p. 63.

5 Para este posible descuido en la edad de Celestina véase lo que dice Peter E. Russell en su edición (Madrid: Castalia, 1991), p. 483n118. A lo largo de este artículo citaremos siempre por esta edición, por plagina. También el artículo de Anne Eesley, "Celestina's Age: Is She Forty-Eight," en Celestinesca 10.2 (noviembre 1986): $25-30$.

6 Juan Ruiz, Arcipreste de Hita, Libro de Buell Amor, ed. A. Blecua, Madrid: Cátedra, 1992, p. 119. En ese "guárdate» habría que englobar asimismo las connotaciones de la barbuda que más adelante pretendo mostrar, que eran conocidas por los lectores de aquella época.

7 Cancionero de Estúñiga, ed. N. Salvador Miguel, Madrid: Alhambra, 1987, pp. 634-635. 
Núñez de Quirós, parafraseando unos conocidos refranes, «ni vi peor compañía,/ que barvas en la muger/ ni cosa de aborrecer/ sino el hombre qu'es sin ellas.»"

Sin lugar a dudas debe haber sido esta vereda, la de la mujer vieja que afea su rostro con la barba, la seguida por la crítica celestinesca, y de ahí tal vez la falta de referencias a lo que puede considerarse un simple epíteto. No obstante, y como tendré ocasión de demostrar a lo largo de este trabajo, existe una serie de significaciones intrínsecas a la barba en la mujer que le confieren una complejidad mayor que la que hasta ahora hemos visto. Complejidad que mucho tiene que ver con el rechazo y oprobio social $\mathrm{y}$, en último extremo, con su relación con el mundo demoníaco. Son significaciones en todo caso que no dejaron de ser puestas de manifiesto por Rojas, y que llevan a Celestina a declarar ante Calisto, en el sexto auto, aquellos calificativos ignominiosos con los que Melibea la nombra en su primer encuentro: «...llamándome hechizera, alcahueta, vieja falsa, barbuda, malhechora, y otros muchos inominiosos nombres con cuyos títulos asombran a los niños" (344 y n42).

Un nuevo recorrido por la poesía cancioneril vuelve a aportarnos otro significado que subyace al mundo de la barbuda, el de la lujuria y su consiguiente vínculo con lo putesco. Contamos con ejemplos más que sobrados de esta relación; baste al caso, dos poemas del Cancionero de Baena donde queda confirmado tal vínculo. Alfonso Álvarez de Villasandino dedica un dicho al Condestable de Castilla para. querellarse contra un "davihuelo," al que en tono insultante le llama "Fijo de algunt vyl barbudo/ et de vyl puta barbuda.» Por su parte, fray Diego de Valencia sale a la defensa de una tal Cortabota, a quien Martín el Ciego le había dedicado un duro poema en donde se le denominaba "puta de costumeria»:

De puta non niego que yo non los sea/ pues traygo devisa de aquesta librea / pero muchas somos de aquesta ginea;/ mas ser costumera, Dios nunca lo quiera./ Sy yo so barbuda (tú) poco los vees/ ca çiego te llaman et ello

8 Cf. Hernando del Castillo, Cancionero General de muchos y diversos auctores, Valencia: Jorge Costilla, 1514, fol. 188r. En otros dichos también encontramos sintetizada esta idea de la mujer barbuda y el hombre lampiño, como los que rezan "Ni de hombre sin barbas, ni de mujer con ellas," o «Hombre lampiño y mujer barbona, malas personas.» 
asy es / "mas por lo que fablas encontra rrevés/ seas confondido por la tu trasera."

Este carácter lujurioso de la barbuda no nos resulta en nada nuevo, pues sin llegar a las prácticas de Celestina, el propio Sempronio termina la presentación de esta vieja con palabras que hablan por sí mismas: «A las duras peñas promoverá y provocará a luxuria si quiere» (234).

Ahora bien, la explicación del por qué de este nuevo significado, hemos de buscarlo una vez más en los tratados médicos. En este caso un compendio anónimo de fines del XV es quien nos aporta la respuesta; pues al mentar las mujeres que poseen pelos en las "quixadas," señala claramente, con una evidente visión fisiognómica, que éstas son muy lujuriosas:

Existen unas mugeres llamadas barbudas, las quales haves de saber que son muy luxuriosas por su caliente complexión, e por consiguiente son de fuerte natura e de varonil condiçión. E la muger bien meca e limpia de pelos, mayormente cabe la boca, según phisonomia, se dize ser de buena complexión, conviene saber, tímida, pavorida, vergonçosa, flaca, mansa e obediente. ${ }^{10}$

Así pues, como más arriba señalaba, la complexión femenina viene a ser determinante en la aparición de la barba, de manera que aquellas mujeres que se acerquen por su calidez y sequedad al hombre son más proclives a la aparición del vello maxilar. ${ }^{11}$ Calidez, que al

9 Se trata de los poemas [ID1324] PN1-184 y [ID1626 R .1625] PN1-500 del Cancionero del Siglo XV de Brian Dutton, III [Salamanca: Universidad, 1991] pp. 142 y 290.

10 Anónimo, Compendio de la Humana Salud, Bib. Nacional de Madrid, I. 51, fol. $7 v$.

${ }^{11}$ Así lo explica Vándalo respondiendo a la pregunta que el joven Etrusco le hace sobre el por qué de la existencia de mujeres con barba: «No se acuerda que le dixe/ que unas mugeres se forman un poco hazia la parte/ que es derecha de la madre que llamamos varoniles/ y aquestas son más calientes que no las otras mugeres/ pero son menos calientes que los hombres y por esto/ crian barva, pero tienen menos barva que los hombres/ por lo semejante desto algunos hombres son fríos/ casi como mugeres y tienen muy poca barva." $C f$. Alonso de Fuentes, Summa de Philosophía natural, Sevilla: Juan León, 1547, sin foliar. 
alejarse de la norma, es explicada como el resultado de una lujuria desorbitada, y de ahí su inevitable unión con el putaísmo. Pues, después de todo, la aparición del vello o la barba femenina ha tenido a lo largo del medievo un cariz lujurioso tan arraigado y extendido que incluso ha llegado a dar lugar a leyendas hagiográficas en las que el vello servía precisamente de contrafactum de esa lujuria. Recordemos el caso de Santa María Egipciaca y Santa María Magdalena, emblemas de la mujer lujuriosa arrepentida, que cubren su cuerpo de un vello que les acerca al mundo de las monstruas salvajes. $Y$ más concretamente al caso que nos ocupa, la historia de Santa Wilgefortis, o Librada como se conocerá en España, nos sirve de punto clave para entender este problema. Cercano el momento del matrimonio, y con él la pérdida de la virginidad, Wilgefortis pide a Dios que le libre de este tormento, y al poco una barba, que sirve de rechazo sexual para el pretendiente, cubre su rostro. $\mathrm{Al}$ enterarse el padre de la joven de tal suceso, la manda crucificar cabeza abajo. En esta misma línea corre la vida de Santa Paula de Ávila, ya de creación plenamente hispánica. Una pastora llamada Paula es deseada por el gobernador Daciano. Un día el gobernador persigue a la pastora que logra esconderse en una capilla en donde, abrazada a los pies de Cristo, pide sea librada de este tormento físico y moral. Al poco una barba comienza a crecer en su cara. Con ello, la pastora consigue salir de la capilla sin ser reconocida por su perseguidor. ${ }^{12}$ Como puede observarse, el crecimiento de la barba o el vello en el caso de estas santas no sólo afea su hermoso aspecto femenino sino que en gran parte las aúna a las salvajes, como he tenido ocasión de indicar anteriormente. ${ }^{13}$

Dejadas a un lado estas historias hagiográficas que vienen a confirmar lo extendido del problema de la barbuda en la literatura

12 Otra historia de una santa barbuda, la de Santa Gala, es la que recoge Gregorio Magno en sus Diálogos. En este caso la barba, aunque sigue siendo el resultado de la guarda de una virginidad espiritual, no aparece ante un posible peligro, sino más bien al contrario, pues Gala, al haber enviudado tras un año de matrimonio, decide dedicar el resto de su vida a Dios, pese a haberle aconsejado los médicos que volviera a casarse ante el peligro de que le creciera la barba, como sucedió. Para un estudio de las santas barbudas y velludas, es imprescindible el trabajo de Carlos A. Vega, "El travestismo santificado: las santas velludas. Reflexiones sobre la abnegación sexual de la mujer en algunos textos hagiográficos medievales" en Figuras de la exclusión femenina: ermitañas, monjas visionarias, barbudas, mujeres pilosas... (ver $\mathrm{n} 1$ ).

13 De forma contraria, como es sabido la perdida del cabello venía a simbolizar la mujer adúltera, lujuriosa, que quedaba marcada ante la sociedad mediante el corte de su pelo. 
medieval, volvamos a Celestina. Hasta este momento hemos visto que el calificativo que Sempronio pone a esta vieja nos hace referencia por un lado a su avanzada edad y por el otro a su relación con la lujuria. Queda no obstante un último aspecto, tal vez el más importante, como es el del vínculo de la barbuda con el mundo de la magia y en último extremo con lo demoníaco. Como sabemos la actuación de Celestina es la de ligadora de los amores de Calisto y Melibea; aunque no obstante también era frecuente que estas "vétulas" tuviesen el poder de desligar. ${ }^{14}$ Así, Bernardo Gordonio en su Lilio de medicina al hablar del amor hereos y de los remedios que han de utilizar para curar la «solicitud melancónica" de aquellos que se encuentran inmersos en las redes del amor femenino, indica, siguiendo muy de cerca a Avicena, que se digan cosas "fediondas" acerca de la amada, y que para ello se busque:

Una vieja de muy feo acatamiento con grandes dientes e barvas e con fea e vil vestidura, e traya debaxo de sí un paño untado con el menstruo de la muger, e venga al enamorado e comience a dezir mal de su enamorada, diziéndole que es tiñosa e borracha e que se mea en la cama e que es epiléptica e fiere de pie e de mano e que es corrompida e que en su cuerpo tiente torondos, especialmente en su natura, e que le fiede el fuelgo e es suzia, e diga otras muchas fealdades, las quales saben las viejas dezir, e son para ello mostradas. ${ }^{15}$

14 Para el problema de la philocaptio imprescindible resulta el libro de Pedro M. Cátedra, Amor y pedagogía en la Edad Media (Estudios de doctrina amorosa y práctica literaria); en concreto el capítulo cuarto dedicado al "Amor y Magia» [Salamanca: Universidad, 1989, pp. 85-112]; y también del mismo investigador «El espacio doctrinal de la bruja” en Figuras de la exclusión femenina: ermitañas, monjas visionarias, barbudas, mujeres pilosas... (ver n1). Asimismo, como siempre que se habla de la magia en Celestina, hay que volver al artículo de Peter E. Russell, "La magia, tema integral de La Celestina," en Temas de "La Celestina" y otros estudios. Del "Cid" al "Quijote" (Barcelona: Ariel, 1978), pp. 241-276. También véase el reciente libro de Francisco Márquez Villanueva, Origenes y sociología del tema celestinesco, Barcelona: Anthropos, 1993. Asimismo la extensa bibliografía compilada (en las notas) por Ana Vian Herrero, "El pensamiento mágico en Celestina, 'instrumento de lid o contienda,'" Celestinesca 14.1 (noviembre 1990): 4191.

${ }^{15}$ Bernardo Gordonio, Lirio de Medicina, ed. John Cull y Brian Dutton, Madison: Seminary of Medieval Studies, 1991, pp. 108-109. 
Viejas barbudas que para alcanzar cualquier propósito no dudan incluso en utilizar los poderes más vetados, aquellos que provienen del demonio. Pues después de todo, la aparición de la barba en la mujer mucho tiene que ver con el aojamiento y las artes diabólicas. No es extraño, por ello, que Juan de Mandavila, en su divulgado Libro de las maravillas del mundo, recogiese el siguiente testimonio al hablar sobre la gente de África:

Un doctor llamado Sigón y otro que dicen Menfodoro, escriben que en África hay mujeres barbudas, las cuales saben tantas artes diabólicas que hacen secar los árboles y matan los niños del ojo...16

Ciertamente este testimonio, aunque se circunscribe a tierras africanas, puede de igual modo extenderse al caso de todas las mujeres barbudas, pues al fin y al cabo, tanto la barba como el aojamiento tienen una generación idéntica. Hemos visto cómo la barba es el resultado de una purgación de humores que al no poder aflorar por donde la naturaleza proveyó, lo hace por medio de los poros de las maxilas. Operación ésta que puede darse por dos motivos concretos, o bien por un exceso de calor--de ahí la relación de la barbuda con la lujuria--que posibilita que los poros de la maxila se abran permitiendo la salida de estos vapores o espíritus; ${ }^{17}$ o bien porque llegado el momento de la menopausia los humores malignos no pueden purgarse como solían y han de buscar otro camino, siendo esos poros maxilares, por su permeabilidad, la salida más común; o incluso puede originarse por la unión de ambos. Pero curiosamente, el mal de ojo o aojamiento, que como sabemos es una de las supersticiones más arraigadas en la cultura mediterránea, era también explicado por los médicos y moralistas como una enfermedad contagiosa producida por la purgación de humores, pero en este caso, sirviéndose de los ojos como adminículo de la

16 Juan de Mandavila, Libro de las maravillas del Mundo, ed. Gonzalo Santonja, Madrid: Visor, 1984, pág. 132.

${ }^{17}$ Precisamente la humedad natural femenina, al igual que la humedad adquirida en los capados impedía que los poros de la maxila se abrieran y surgiera la barba, como señala López de Corella al dar respuesta a la pregunta de "¿Por qué no nasce al capado barba ni a la muger?": "La muger y los capados/ por mucha umedad tener/ tienen los poros cerrados/ estanto tan apretados/ no pueden pelos nascer/ y el calor poco que tienen/vapor no pueden alçar/y si suben no convienen/ para pelos se engendrar" [A. López de Corella, Trezientas preguntas de cosas naturales..., Valladolid: Francisco Fernández de Córdoba, 1546, pregunta CXV]. 
expulsión de estos vapores malignos. Así, entre otros, fray Martín de Castañega escribe un tratado contra las vulgares supersticiones, en donde el problema del aojamiento, al que se dedica todo un capítulo, se explica con los mismos términos que lo hacían médicos medievales como Álvarez Chanca: ${ }^{18}$

La virtud natural expulsiva, que es una de las virtudes de la potencia nutritiva, expele y lanza fuera del cuerpo todas las impuridades que se tornan en sustancia $y$ mantenimiento del cuerpo, y lo que es más grueso expele y echa por las partes inferiores que naturaleza para ello proveyó y señaló... y lo que es más sotil expele por las vidrieras de los ojos; y asi salen por los ojos como unos rayos las impuridades y suciedades más sotiles del cuerpo, y cuanto más sotiles, tanto son más penetrantes y más inficionan. ${ }^{19}$

Se establece, pues, una correlación transcendente entre la aojadora y la menopáusica, y en último extremo con la barbuda, como una única persona; ya que los humores, que no encuentran su forma corriente de purgación, salen por aquellos lugares donde más fácil resulta, es decir por los ojos o por los poros de la maxila. Esta relación, en mi opinión, explica la existencia de refranes en donde se puede vislumbrar claramente un rechazo social de la barbuda, como aquel latino

18 Para el problema del mal de ojo en la edad media véase mi La literatura de fascinación en la Península (siglos XV y XVI), Trabajo de Grado presentado en la Universidad de Salamanca [inédito]. También mi «La literatura de fascinación en la Península: una incursión por los tratados de mal de ojo de los siglos XV y XVI," en Literatura fantástica. Una nueva visión y sensibilidad del texto como creación, coord. Julia Barella, Anthropos, pp. 154-155 (marzo-abril, 1994): 106-111.

19 La obra de este franciscano burgalés fue el resultado de los datos obtenidos durante su labor como inquisidor del Santo Oficio en el foco de superstición que asoló Logroño hacia 1527. Su Tratado de las supersticiones y hechicerias, vería una única edición, la salida de la imprenta logroñesa de Miguel Eguía [Véase la edición de Madrid: Sociedad de Bibliófilos Españoles, 1946, pp. 71-74]. Por su parte, Pedro Ciruelo también dedica un capítulo al tema del aojamiento en su conocido tratado reprobatorio, pero a diferencia de Castañega, su texto no está en consonancia con las explicaciones físicas del mal, pues apenas demuestra tener interés por ellas, que deja en manos de los médicos, para centrarse sobre todo en la recriminación abierta de esta enfermedad que había pasado a formar parte del amplio cajón de supersticiones populares. Véase la edición de Alva V. Ebersole [Valencia: Albatros, 1978], pp. 95ss. 
que reza: «Mulierem barbatam eminus esse salutandam» [«A la mujer barbuda de lejos se la ha de saludar»]; ${ }^{20}$ o aquel que recoge Francisco de Espinosa en su Refranero cuyo enunciado marca aún más este rechazo: "Mujer barbuda, de lexos me la saluda, con tres piedras que no con una.». A través de ellos nos damos cuenta que la mujer barbuda debía ser alejada sintomáticamente de la mirada, llegando incluso a su lapidación para arrojarla fuera de la vista. La explicación a tal exclusión la encontramos en G. Battista della Porta, quien al hablar de la "donna barbuta" lo hace en los siguientes términos:

La barbuda es de pésima costumbre, los hombres vulgares le han dedicado un proverbio, "femina barbuta con pietre la saluta." Dice Miguel Scoto que la barbuda es de gallarda vida, de mucha lujuria y de condición masculina por la calidez de su complexión. Su condición natural y el calor son los causantes del crecimiento del pelo que cubre su rostro. Es por ello que la barbuda debe ser tenida como presagio de una gran desgracia venidera... .22

¿Presagio de una gran desgracia venidera tan sólo? Creo que no. En mi opinión la barbuda, además de ser considerada como una señal de mal agüero, ha de ser tenida como una fascinadora en potencia; es decir como una mujer capaz de contagiar el mal de ojo a aquellas personas

${ }^{20}$ Eleanor S. O'Kane, recoge una variante "A muger barbuda, de luenne me la saluda" [Refranes y frases proverbiales españolas de la Edad Media, en Anejos del Boletín de la Real Academia Española de la Lengua, II, Madrid: Aguirre Torre, 1959, pág. 59]. Por su parte Sebastián de Horozco en su conocido Teatro Universal de Proverbios indica respecto al refrán "La muger barbuda/ de lejos me la saluda": Por malinos son notados/aquellos que la natura/ quiso haçer señalados/y por falsos reputados/ de qualquiera criatura./ Para lo qual nos ayuda/ la pratica muy usada/ y es que la muger barbuda/ de lexos me la saluda/ como cosa señalada [Citamos por la edición de José L. Alonso Hemández, GröningenSalamanca: Universidad, $1986, \mathrm{n}^{\circ} 1450$, pág. 316]. Véanse también los números 22a y 327 del Vocabulario General de Refranes de Correas. Asímismo Sebastián de Covarrubias, Tesoro de la lengua castellana o española, ed. Martín de Riquer, Barcelona: Alta Fulla, 1987, p. 192 [voz 'barba'].

${ }^{21}$ Francisco de Espinosa, Refranero (1527-1547), ed. de Eleanor S. O'Kane, Anejos del Boletín de la Real Academia Española de la Lengua, XVIII, Madrid, 1968.

22 G. Battista della Porta, Della fisonomia dell'huomo, Napoli: Gio Giacomo Carlino, 1610, pág. 210. La traducción es mía. 
susceptibles de captar, a través de la vista, los espíritus malignos que arroja la barbuda, quedando con ello aojados y expuestos incluso a la muerte. Es precisamente el carácter aojador el que es temido por la vulgar gente que, a fin de evitar el contagio, han de alejarse lo más posible de esta peculiar mujer, incluso sirviéndose de la fuerza intimidatoria mediante el lanzamiento de piedras. Pues, al fin y al cabo, como bien exponían los autores que trataron sobre el aojamiento, el poder del rayo fascinador se encontraba limitado espacialmente, de ahí que el contacto o el alejamiento con el aojador sea decisivo.

Esta larga digresión en la que se han ido agrupando sistemáticamente todas las connotaciones que subyacen a la barbuda tiene razón de ser en el análisis que a continuación voy a realizar. En cuatro momentos de la obra se llama a Celestina barbuda. En el primer auto, cuando Sempronio habla a Calisto de Celestina: «Días ha grandes que conozco, en fin desta vezindad, una vieja barbuda que se dize Celestina»; al inicio del tercer auto, cuando Sempronio marcha a casa de la vieja, y señala en un aparte el sosiego con el que anda Celestina tras haber recibido el primer pago a su labor: “QQué espacio lleva la barvuda!»; en el cuarto auto, Melibea será la que en tono insultante la llame "desvergonçada barvuda" al percatarse del juego que se trae entre manos Celestina; y por último, como ya indiqué más arriba, en el sexto auto, cuando Celestina relata ante Calisto los insultos que tuvo que escuchar de Melibea tras exponer su «embaxada»: «...llamándome hechizera, alcahueta, vieja falsa, barbuda, malhechora, y otros muchos inominiosos nombres... ." En los cuatro casos quedan evidenciadas, a mi parecer, las tres significaciones que he reconstruido acerca de la mujer barbuda: que suele tratarse de una mujer vieja, lujuriosa y con cierta relación con los poderes demoníacos.

Lo de vieja y lujuriosa, además de por un conocimiento explícito de la obra, queda constatado en ese "espacio" andar que tan a menudo aparece en este texto, así como por la profesión de Celestina. Más compleja, en cambio, es su relación con el mundo brujeril y los poderes demoníacos. Cuando Celestina se marcha en el cuarto auto, cena primera, a casa de Melibea, tras haber invocado al demonio, recibe toda una serie de indicios que se presentan como agüeros favorables a la empresa que pretende llevar a cabo. $Y$ así lo indica explícitamente:

Todos los agüeros se adereçan favorables o yo no sénada desta arte; quatro hombres que he topado, a los tres llaman Juanes y los dos son cornudos. La primera palabra que oy por la calle fue de achaque de amores. Nunca he tropezado como otras vezes. Las piedras 
parece que se apartan y me fazen lugar que passe, ni me estorvan las haldas, ni siento cansancio en andar. Todos me saludan. Ni perro me ha ladrado, ni ave negra he visto, tordo ni cuervo ni otras nocturnas. (300 y nn19 y 22)

Los editores y críticos de Celestina han sabido sacar partido a estos presagios elaborando teorías bastante lógicas al caso; ${ }^{23}$ pero no obstante ninguno de ellos, que conozca, se ha parado a analizar el significado de ese "Todos me saludan" que sin lugar a dudas hay que ponerlo en relación con los refranes que más arriba aludía: «Mulierem barbatam eminus esse salutandam," pues recordemos las palabras de della Porta: «la barbuda debe ser tenida como presagio de una gran desgracia venidera... ." Es decir, la gente saluda a Celestina porque no la consideran en ese instante mal agorera, lo cual sirve de favorable presagio para la vieja. ${ }^{24}$

Pero además no puedo por menos que volver a destacar la relación de la barbuda con el aojamiento, que en el caso de Celestina es fácilmente rastreable. En dos ocasiones se habla claramente del mal de ojo; una primera en el quinto auto, cena segunda, cuando Celestina se burla de Sempronio valiéndose de la ambigüedad del término aojar diciendo que si va a andar con un arco de casa en casa: “ $i . .$. tirando a páxaros y aojando páxaras a la ventanas?» $(331, n 17)$; y una segunda en el décimoquinto auto, cena tercera, cuando Elicia recrimina los amores de Calisto y Melibea causantes de la muerte de Sempronio y Pármeno, deseándoles todo mal, mediante un locus luctuosus, en el que los árboles se secarán con la vista aojadora de los dos amantes:

Tórnese lloro vuestra gloria, trabajo vuestro descanso.

Las yervas deleytosas donde tomáys los hurtados solazes

23 Véase la nota 20 de la página 300 de la edición de Russell. También las páginas 150-151 n6, de la edición de Dorothy S. Severin [Madrid: Cátedra, 1990].

24 No se me escapa lógicamente otra posible explicación como es la de relacionar ese "saludan" con la labor benéfica de los saludadores, personas que, como de sobra es sabido, poseían unos poderes positivos capaces de curar males varios como la rabia, y de ahí el significado intrínseco de la palabra saludar. Saludadores que también eran objeto de estudio y debate en todos los tratados antisupersticiosos, máxime cuando podian darse casos de picaresca y embaucamiento. De igual modo no puedo dejar de anotar el paralelismo de los saludadores con la «salutatio virginis" del Arcángel San Gabriel a la virgen María, por parecerme más que evidente. 
se conviertan en culebras, los cantares se os tornen lloro, los sombrosos árboles del huerto se sequen con vuestra vista, sus flores olorosas se tornen de negra color. ${ }^{25}$

Como puede observarse, ninguna de estas referencias sirve a nuestro propósito, pero al menos nos dan pie para hablar de este mal sin columpiarnos en la cuerda floja de la hipótesis, al quedar evidenciado el conocimiento de esta enfermedad supersticiosa por parte de Rojas. ${ }^{26}$

Con ello, existen tres momentos claves en los que a mi modo de ver queda bastante clara la actitud aojadora de Celestina. Así, en el primer auto, cena sexta, cuando Sempronio comenta a la vieja que la necesidad que Calisto tiene de ella, pues arde de amores por Melibea, les puede reportar pingües beneficios, Celestina replica: «Bien as dicho; al cabo estoy. Basta para mi mescer el ojo." Mas tarde, en el tercer auto, cena primera, Sempronio y Celestina dialogan sobre cómo van a conseguir el negocio de Calisto con Melibea, la barbuda hace referencia a su labor de buhonera para poder entrar en casa de Alisa: «Por que donde me tomare la boz me halle apercibida para les echar cevo o requerir de la primera vista” (288). Por último, en el tercer auto, cena segunda, tras haber conjurado al diablo para que, por medio del aceite serpentino, se encierre en la madeja que venderá a Melibea, señala claramente:

$Y$ con ello de tal manera quede enredada que, quanto más lo mirare, tanto más su coraçón se ablande a conceder mi petición, y se le abras y lastimes del crudo y fuerte amor de Calisto, tanto que, despedida toda honestidad, se descubra a mí y me galardone mis passos y mensaje. (294)

«Basta para mí mescer el ojo»; "requerir de la primera vista» y "quanto más lo mirare» son tres frases que hay que interpretar como uno de los tipos de aojamiento que tradicionalmente se solían describir, la de

25 Celestina, pp. 625-626, nota 15 . Otra referencia al mal de ojo, aunque no explícita, la podemos ver en el "vajarisco" que aparece en el prólogo, pues como sabemos se trata del animal aojador por excelencia $(198, \mathrm{n} 14)$.

${ }^{26}$ Véase al caso, además, el artículo de D. J. Gifford, «Magical Patter: The Place of Verbal Fascination in La Celestina," in Mediaeval and Renaissance Studies on Spain and Portugal in Honour of P. E. Russell, Oxford: Society for the Study of Mediaeval Languages and Literature, 1981, pp. 30-37. 
la fascinatio amoris. ${ }^{27}$ Fascinación de amor que mucho tiene que ver con el arte de hechizo tal y como lo describe uno de los tratadistas sobre magia natural más importante del Renacimiento, Cornelio Agrippa. Agrippa define el hechizo como:

Una ligadura que pasa del espíritu del hechicero al corazón del hechizado a través de los ojos. El instrumento del hechizo es el espíritu, esto es, un vapor puro, límpido, sutil, generado por el calor del corazón y la sangre más limpia. Dicho vapor emite sus rayos a través de los ojos, y en su emisión esos rayos transmiten un vapor espiritual que contiene la sangre, como ocurre con los ojos legañosos y enrojecidos de una persona: su rayo emitido a los ojos de quien le está mirando arrastra consigo el vapor de la sangre corrompida, y los contagia con la misma enfermedad. Digamos, pues, que un ojo mirando fijamente a alguien proyecta sus rayos sobre los ojos contrarios, en virtud de la propia agudeza de sus rayos, que son el vehículo del espíritu. Así, este espíritu extraño va penetrando lentamente-- como si lo dominara-en los ojos del hechizado, le estimula su corazón e impregna su espíritu... Tal es la fuerza del hechizo, especialmente cuando son los vapores de los ojos los esclavos de las pasiones. Ésta es la causa por la que los hechiceros utilizan colirios, ungüentos, ligaduras y similares, para preparar y condicionar mejor el espíritu.... . ${ }^{28}$

27 El aojamiento se dividía tradicionalmete en natural y diabólico. A la vez, y dentro del aojamiento diabólico, se hablaba de una fascinación por amor, por odio y por envidia. El natural era objeto de atención de los médicos, pues era considerado como el resultado de una discrasia. Por su parte el diabólico, que se acerca más en sus premisas al que vulgarmente conocemos como mal de ojo, era curado no por los físicos curadores de cuerpos, sino por religiosos curadores de almas. Por su parte la fascinatio amoris comparte campo con el enamoramiento y el hechizo. Para esto último, véase lo que dice G. Battista della Porta en su De occultis litterarum notis (Montis Beligardi: Jacobo Foillet, 1593, fol. 63a).

${ }^{28}$ [Citamos por la edición de Bárbara Pastor de Arozena, Madrid: Alianza, 1992, pp. 189-190]. El De occulta philosophia de Agrippa, pese a que no salió a luz hasta 1533, apenas dos años antes de la muerte de su autor, sabemos que estaba concluido antes de 1531, pues desde ese año intentaron varios editores llevar a cabo su publicación sin éxito. Es una obra que auna las corrientes de la magia natural y de la cabalística más importantes de su época, como son los tratados de 
Así pues, Rojas deja entrever la capacidad aojadora que posee Celestina, capacidad que le permite hechizar a Melibea e inculcarle un amor loco por Calisto. Aojamiento que puede realizar directamente a través de sus ojos: "Basta para mí mescer el ojo»; "requerir de la primera vista," o bien a través de una ligadura, en este caso a través del hilado, de modo que "quanto más lo mirare," más encenderá en su corazón el amor. $^{29}$

Para concluir me gustaría destacar un último aspecto que, aunque nada tiene que ver con Celestina, cierra perfectamente el campo de connotaciones de la barbuda en la obra de Rojas. En el séptimo auto, cena primera, Celestina dialoga con Pármeno intentando convencerle para que haga las paces con Sempronio, a fin de llevar a cabo juntos el negocio de Calisto. $Y$ en un momento dado, Pármeno memora a su madre lo que obliga a Celestina a recordar a Claudina: « $\mathrm{O}$, qué graciosa era! ¡O, qué desembuelta, limpia, varonil!" Sobre ese "varonil» Russell, con buen criterio, anotaba la ambigüedad de sentido, pudiéndose entender tanto "esforzada" como, "con intención cómica," «hombruna" $(364$, n32). Pero aún hay más. La barbuda representaba en otra de sus significaciones ese valor de perfección andrógina, alejada de la inteligencia común femenina y cercana, por lo tanto, al entendimiento y virtud del hombre. Con ello, entendemos el juego de sentidos que utiliza Jaume Roig en su Espejo o Libro de Consejos. En el libro segundo, tercera parte, el narrador cuenta cómo se casa con una viuda sobre la que el viejo presbítero mosén Company dijo: «...quiero proporcionaros una esposa barbada: una que es tenida en gran aprecio, y es, hoy por hoy, la mujer cumbre entre las viudas.» Con el tiempo resulta que dicha viuda era toda una farsa, pues era mayor de lo que decía, estéril, lujuriosa, fea, sucia, etc., lo que lleva a decir al narrador, con no poca ironía: «El cura,

Ficino o Pico della Mirandola, pero sin obviar en ningún momento los avances que esta ciencia tuvo en la edad media de la mano de Alberto Magno, Roger Bacon, Arnau de Vilanova, y un largo etc.

29 Bastante significativas resultan al caso las siguientes palabras que dice el Arcipreste de Talavera acerca de la utilización que hacen las mujeres de su ojo: «Pues, las señales que saben fazer del ojo estas son diversas: que mirando burla al ombre, mirando mofa al ombre, mirando halaga al ombre, mirando enamora al ombre, mirando falaga al hombre, mirando muestra saña, mirando muestra ira echando aquellos ojos de través. Más juegos sabe fazer la muger del ojo que non el embaidor de manos» (Alfonso Martínez de Toledo, Arcipreste de Talavera o Corbacho, ed. Michael Gerli, Madrid: Cátedra, 1981, p. 168]. 
cuando de ella me habló, bien dijo "Barbuda"; a lo que el refrán añade: "¡de lejos la saluda!" ${ }^{30}$

No necesita mayor explicación dicho pasaje pues, a raíz de lo que aquí he venido indicando, queda bastante claro ese último matiz, en el que el adjetivo "barbuda" adquiere un significado de virtuosa por su acercamiento a la inteligencia varonil. ${ }^{31}$ Por otra parte, y volviendo a la ambigüedad, no olvidemos lo que decía el compendio médico anónimo sobre las barbudas, "son de fuerte natura e de varonil condiçión," calificativos que redundan en la idea de "hombrunas" y que se recogen en todos los tratadistas que hablan de estas peculiares mujeres. ${ }^{32}$

Con todo, creo haber podido demostrar a lo largo de este trabajo el completo y complejo campo de significaciones que la barbuda posee. Así, se puede comprender el éxito de esta peculiar mujer--vieja, hechicera, lujuriosa, mal agorera, aojadora--en la literatura, cuya aparición puede ser rastreada abundantemente en las centurias posteriores a Celestina.

\footnotetext{
${ }^{30}$ Debemos la noticia de este texto a Lola Badía. He utilizado en la cita la versión castellana de R. Miquel y Planas, Barcelona: Casa Miquel-Rius, 1942, pp. 70 y 72 respectivamente. Quien desee consultar el original valenciano puede hacerlo, entre otras, por la edición de Barcelona: Barcino, 1928, pp. 77 y 79.
}

31 Con ese sentido, pero con un carácter de valía ultrasexual, lo usa el Padre Báñez para describir a Santa Teresa en su declạración al Proceso de Beatificación de la mística: "Fray Juan de Salinas, que fue provincial de los dominicos, preguntó al Maestro Báñez sobre una tal Teresa de Jesús, previniéndole que no había de fiar de virtud de mujeres. Por toda respuesta le dijo Bánez: "Véala Vuestra Paternidad, y después me diga que le parece." Así lo hizo el reverendo Salinas, y en cuanto topó con Báñez espetó a éste: “ $\mathrm{O}$, Padre, me habíais engañado, que decíais que Teresa era mujer; a fe mía, que no es, sino hombre varón, y de los muy barbados" [C $f$. Biblioteca Mística Carmelitana, Burgos: Monte Carmelo, 18, 9]. Además no hay que perder de vista las historias hagiográficas en donde las mujeres adquieren una barba física como contrafactum de la barbuda lujuriosa; barba física que por su origen virtuoso las acerca en gran medida al entendimiento varonil.

32 «Que llamamos varoniles," señalaba Alonso de Fuentes en la cita que traía anteriormente en nota. Por su parte, López de Corella, glosa la respuesta, que reproduje no ha mucho también en nota, con palabras así de claras: "Algunas mugeres ay que suelen tener pelos en las barbas, $y$ éstas son calientes y varoniles, las quales son furiosas y de buena fuerça, y ansí dizen "que de lexos las cumple saludar."» 
Quiero concluir este artículo con un único ejemplo, tal vez el más significativo por la pluma que lo escribe, en donde de nuevo queda constatado el éxito literario de la barbuda y su relación con el mundo hechiceril. En el conocido Coloquio de los perros de Cervantes, en un momento dado Berganza relata un episodio en el que se encuentra implicada la Cañizares, y señala:

Fuese la gente maldiziendó a la vieja, añadiendo al nombre de hechicera el de bruxa, y el de barbuda sobre vieja. $^{33}$

\section{Colcitina.}

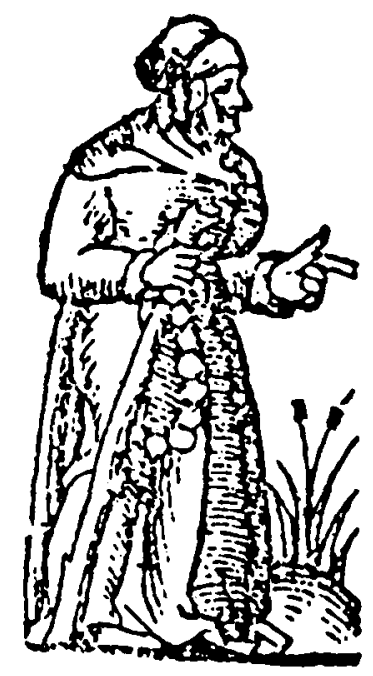

Sevilla: J. Cromberger, 1535

33 Miguel de Cervantes Saavedra, Coloquio de los perros, en Obras completas (Madrid: BAE, 1943), p. 237. 


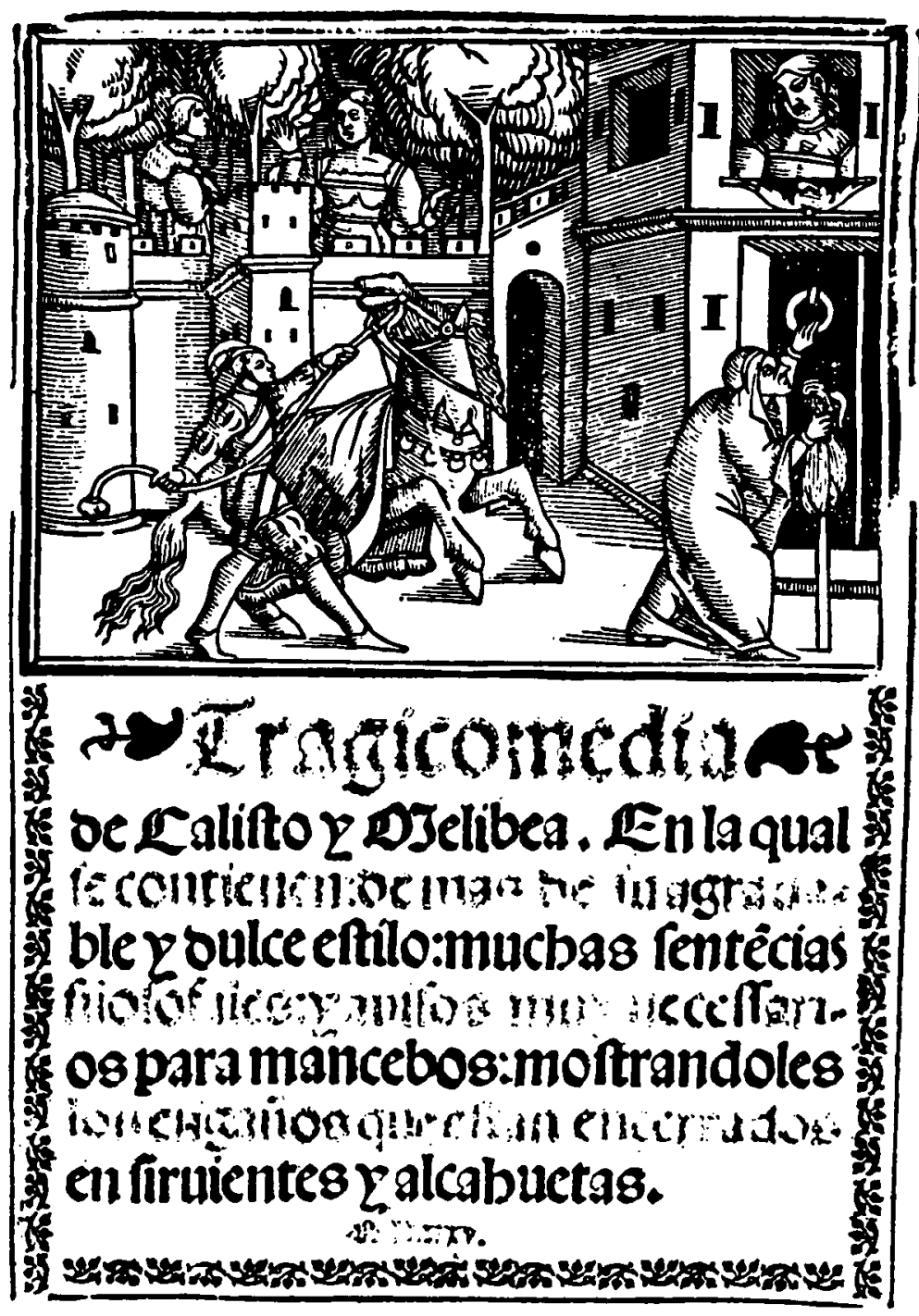

Sevilla: J. Cromberger, 1535 